\title{
Neurocysticercosis: a reversible and rare cause of seizure in the developed world
}

\author{
Kevin J Kobes, Pouneh Pasha, Charlotte Dandurand
}

Faculty of Medicine, University of British Columbia, Vancouver, British Columbia, Canada

Correspondence to Kevin J Kobes,

Kevin.kobes@alumni.ubc.ca

Accepted 11 October 2018

\section{DESCRIPTION}

A 22-year-old man, originally from India, presented to an emergency department in Canada with a new-onset seizure and collapse associated with a few seconds of right eye and tongue deviation. This event occurred following 6 weeks of difficulty concentrating and unilateral left-sided headache. On examination, no focal neurological deficits were found. A non-contrast CT head was requested which showed a left-sided occipital lesion. A follow-up brain MRI revealed the 'hole-with-dot' lesion pathognomonic for neurocysticercosis (NCC).

NCC is caused by the tapeworm Taenia solium and is the most common parasitic infection of the central nervous system, endemic to many low-income countries worldwide. T. solium is transmitted among humans via the faecal-oral route, with pigs acting as an intermediate host. Humans are a definitive host for the intestinal tapeworm which produces eggs containing an infective embryo (oncosphere). This embryo can actively cross the intestinal wall into the blood stream and deposit in various tissues in the body. ${ }^{1}$

NCC is recognised when $T$. solium embryos deposit into the brain. The first of three stages in NCC consists of the 'colloidal' stage where larvae exist as cystic vesicles containing a scolex (figure 1A). These cysts can persist for years before degenerating in the 'nodular' stage, which in turn can lead to vasogenic oedema. This explains the epileptogenicity of NCC. It then enters the 'calcified' stage. ${ }^{1}$

NCC can be diagnosed solely on neuroimaging with visualisation of a scolex within a cystic lesion. This gives the pathognomonic 'hole-with-dot' appearance (figure 1B). ${ }^{2}$ Other neuroimaging features suggestive of parenchymal NCC include: well-demarcated and round lesions, non-enhancing with intravenous contrast and less than $20 \mathrm{~mm}$ in diameter. ${ }^{2}$ Serological testing using the enzymelinked Immunoelectrotransfer blot (EITB) assay can support the diagnosis in addition to clinical and radiological findings. ${ }^{2}$

NCC is the primary cause of preventable epilepsy in low-income and middle-income countries with millions estimated to be infected worldwide. ${ }^{1}$ NCC is commonly observed in India with single enhancing nodules being more frequently seen in individuals younger than 30 years of age. ${ }^{1}$ Late-onset, generalised, tonic-clonic seizures are the most common presentation of NCC with the onset of seizures typically occurring between the ages of 20-49 years. $^{2}$ In the USA, $2 \%$ of emergency department visits due to seizure were caused by NCC. ${ }^{1}$ Although not endemic to developed countries, there is an increasing number of patients with NCC in developed countries due to increasing rates of international travel and immigration. ${ }^{1}$ Therefore, when presented with cases of late-onset seizures, NCC should be taken into

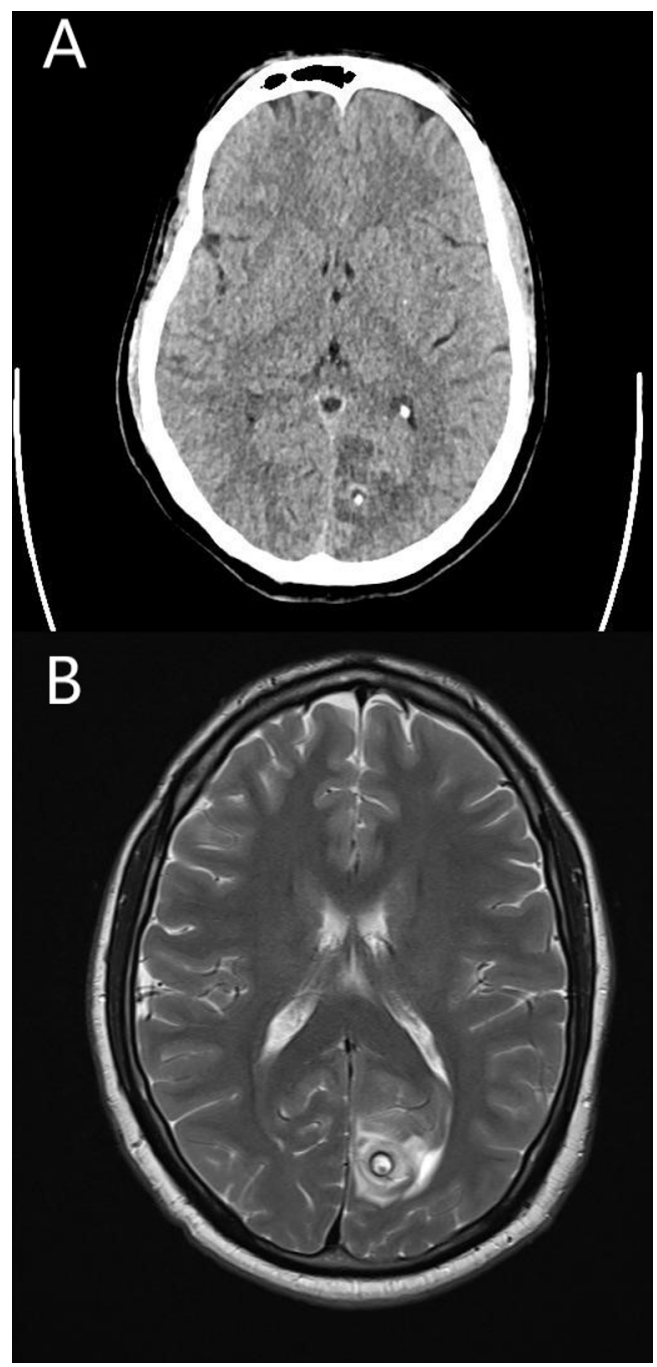

Figure 1 (A) Non-contrast axial CT head shows a focus of calcification in the left occipital region with surrounding oedema suggestive of either neurocysticercosis (NCC) or a neoplastic process. (B) MRI scan of the head using the T2 sequence shows a single well-demarcated, round $12 \mathrm{~mm}$ intra-axial lesion with a thick hypointense rim. The cystic appearance with visualisation of the scolex inside gives the pathognomonic 'hole-with-dot' sign of NCC. Diffuse hyperintense signal surrounding the lesion is consistent with vasogenic oedema. 
consideration as it can no longer be considered an 'exotic' disease in the developed world.

Our patient was started on phenytoin for control of seizures. He was then placed on steroids and initiated on a 14-day course of albendazole, given the paradoxical increased risk of seizure

\section{Learning points}

The "hole-with-dot" sign seen on neuroimaging is pathognomonic for neurocysticercosis and sufficient to diagnose NCC in the absence of further clinical data.

- Neurocysticercosis should be considered in patients who present to emergency with late-onset seizure as incidence of NCC is increasing in the developed world due to increasing rates of immigration and international travel. secondary to the start of treatment. He will have a follow-up MRI scan in 6 months to ensure resolution of lesion, at which point the decision for continuation of phenytoin will be made.

Contributors PP identified the case. KJK and PP performed a literature review and drafted the article and provided the pictures. $C D$ and KJK revised the report and CD approved the article for submission.

Funding The authors have not declared a specific grant for this research from any funding agency in the public, commercial or not-for-profit sectors.

Competing interests None declared.

Patient consent Obtained.

Provenance and peer review Not commissioned; externally peer reviewed.

\section{REFERENCES}

1 Garcia HH, Nash TE, Del Brutto OH. Clinical symptoms, diagnosis, and treatment of neurocysticercosis. Lancet Neurol 2014;13:1202-15.

2 Del Brutto OH, Nash TE, White AC, et al. Revised diagnostic criteria for neurocysticercosis. J Neurol Sci 2017;372:202-10.

Copyright 2018 BMJ Publishing Group. All rights reserved. For permission to reuse any of this content visit

http://group.bmj.com/group/rights-licensing/permissions.

BMJ Case Report Fellows may re-use this article for personal use and teaching without any further permission.

Become a Fellow of BMJ Case Reports today and you can:

- Submit as many cases as you like

- Enjoy fast sympathetic peer review and rapid publication of accepted articles

- Access all the published articles

Re-use any of the published material for personal use and teaching without further permission

For information on Institutional Fellowships contact consortiasales@bmjgroup.com

Visit casereports.bmj.com for more articles like this and to become a Fellow 